\title{
NOT A S
}

\section{LA CASI MUERTE DE FELIPE ALFAU}

Hace ya muchos años fue en Nueva York. Llegué por necesidad a trabajar en el periódico La Prensa y tenía veinte años. Allí me presentaron a dos señoritas españolas, espirituales, vestidas de negro. Jesusa se llamaba la una y ésta casó con Antonio Solalinde; la otra, que tenía un nombre que parecía diminutivo, casó con Teixedor. Nombraban en las conversaciones a un hermano pequeño, de nombre Felipe. Un día yo les dije: "ese chico va a ser escritor". Esto pasó a fines de 1918. Después me olvidé de Felipe y la señora Jesusa se murió.

Veinte años más tarde, otra vez en Nueva York, Ernesto Montenegro me dijo: "vamos a visitar a mi amigo Felipe Alfau". Fuimos a Greenwich Village, donde vivía. Ya era hombre, cetrino, muy español. En la puerta de su casa, en la acera, puso una garrafa de vino. Tenía familia y unos chicos - creo que de él-que echaban codiciosas miradas a los vasos. El barrio era pobre y la casa era pobre, pero el vino y la buena amistad encendieron una conversación de seis horas.

Veinte años más tarde. Hoy, 9 de noviembre de 1956, he comprado un libro intitulado Thirteen Great Stories, y es en Berkeley, California. Entre otros nombres consagrados -James Joyce, Pirandello, Scott, Fitzgerald, Katherine Anne Portes- está el nombre de Felipe Alfau. Leo su cuento The Beggar (El mendigo) y siento la fuerte emoción de un mundo olvidado. El cuento es una pequeña obra maestra, una breve síntesis del alma española. $\mathrm{Y}$ leo en la breve introducción que Felipe Alfau nació en España, se vino de catorce años a los 
Estados Unidos, que quiso ser compositor y director de orquesta, que es autor de una comedia titulada Locos y que en los últimos veinte años ha sido traductor en un banco de Nueva York y no había escrito nada.

Ser traductor en un banco es duro ejercicio, por eso escribió Góngora :

\author{
Amarrado al duro banco \\ de una galera turquesca...
}

Pero ser traductor en un banco y tener el talento creador de "Felipe Alfau es casi un crimen. Claro está que el mayor crimen es ser pobre. Al escribir esto oigo una vocecilla traviesa que me dice:

- iSe olvida usted que hay "fundaciones" tales como la Guggenheim, la Rockefeller, la Carnegie? Sí, me olvidaba de ellas, como se olvidaron de Felipe, ese talento que vive entre números en un banco de Nueva York. ¿Qué no habría escrito Felipe Alfau en cuarenta años? ¡Esta es la vida, Azorín; ésta es la vida!

Así y todo, esta lectura de los dos mendigos españoles, en inglés, determinada por una casualidad, me recuerda capítulos de la novela de mi vida: las señoritas Alfau en La Prensa; la garrafa de vino en Greenwich Village, y la casi-muerte de un poeta.

\author{
ARTURO TORRES-RIOSECO \\ Universidad de California, Berkeley
}

\title{
UNA POESIA PANEGIRICA DE GERTRUDIS GOMEZ DE AVELLANEDA
}

$\mathrm{E}$ N 1854, con ocasión del quincuagésimo aniversario de la muerte de José Nicolás de Azara, diplomático, literato, mecenas y filántropo, Basilio Castellanos de Losada, "historiador de la casa de Azara, cronista y anticuario de la casa y estados del Duque de Osuna y del infantado, director fundador de la Academia Española de Arqueología", etc., etc., concibió 
el plan de un homenaje dedicado a la memoria de este gran hombre, para lo cual solicitó la colaboración de las personas distinguidas de España y el extranjero.

Utilizó para ello los elogios de éstos recogidos en el grueso y curioso Album de Azara: "Corona Científica Literaria, Artística de las Universidades, Academias, Maestranzas, Cuerpos Científicos y Patrióticos, el Cuerpo Diplomático y Hombres Políticos Nacionales y algunos Extranjeros consagrado a la buena Memoria del Insigne Caballero Aragonés el célebre Diplomático y distinguido literato español D. José Nicolás de Azara y Perera, primer marqués de Nibbiano".

La publicación se hizo en Madrid, en 1856. Entre los numerosos colaboradores encontramos a Gertrudis Gómez de Avellaneda, que por entonces moraba en Madrid, quien ofreció una composición poética que no mencionan sus biógrafos ni está incluída en las ediciones de sus obras. Nos permitimos reproducirla a continuación :

\section{Al primer Marqués de Nibbiano}

España le dio cuna, gloria el mundo, pues fue tan gran varón en todas partes, padre del pueblo, numen de las artes, ángel de paz, político profundo.

Su elocuencia feliz no se escuchó en vano el nuevo César que amagaba a Roma; al genio de la guerra el suyo doma y Salvador le aclama el Vaticano.

Otra noble misión gloriosa llena cuando al sonar su voz, valiente y pía los franceses cautivos en Turquía aflojar sienten su fatal cadena,

y la fiera República que leyes quiso dictar a pueblos asombrados le admiró defensa de sus soldados y amigo fiel de sus proscritos reyes.

Donde do quier inolvidable ejemplo, fue de su casa en el hogar tranquilo donde halló siempre el infortunio asilo, $y$ el humano saber ilustre templo. 
Por eso, Azara, descargar sus iras pudo la muerte sin herir tu gloria, $\mathrm{y}$ aun le rinden tributo a la memoria las nacionales y extranjeras liras!

Gertrudis Gómez de Avellaneda (Madrid, 1855, op. cit., pág. 268)

A pesar de que trabajó sobre materiales bastante conocidos, la Avellaneda logra, sin embargo, darnos una admirable condensación de la vida y los hechos del español insigne. ${ }^{1}$

JoSEPh G. Fusilla

Northwestern University

\section{UNAS NOTAS SOBRE LA POESIA DE MARGARITA ABELLA CAPRILE}

$\mathrm{L}^{\wedge}$

A Argentina puede enorgullecerse del crecido número de escritoras de primera clase, que le han dado prestigio $\mathrm{y}$ renombre en el siglo veinte. Entre las poetisas hay algunas personalidades sobresalientes desde aquella original generación que surgió en el segundo decenio de nuestro siglo y que cuenta con nombres importantes empezando por el ilustre de Alfonsina Storni, los de sus contemporáneos Rosa García Costa, Margarita Abella Caprile, María Raquel Adler, María Alicia Domínguez, Emilia Bertolé, y algo más de cerca de nosotros Norah Langè, Mara de Villarino, Ana María Chouhy Aguirre, María Granata, Fryda Schultz de Mantovani, Silvina Ocampo, por no mencionar sino algunos. En artículos anterio-

1 La biografía de Azara puede leerse en casi todas las grandes enciclopedias -Espasa, Grande Encyclopédie, Enciclopedia Italiana-y en diccionarios biográficos como Biographie Universelle, Nouvelle Biograpbie Générale, etc. Estas, empero, no aluden al papel de Azara en el rescate de los franceses cautivados por los turcos, empresa realizada en la época en que se encontraba como embajador en Portugal. Para informaciones biogtáficas más extensas véase: Basilio Sebastián Castellanos de Losada, Historia de la vida civil y politica del célebre diplomático $y$ distinguido literato español el magnífico caballero D. José Nicolás de Azara (Madrid, 1849-50, 2 tomos), muy probablemente la fuente inmediata de que se sirvió Avellaneda. 
res nos hemos ocupado de algunas de estas poetisas y en el presente quisiéramos referirnos a la obra lírica de Margarita Abella Caprile.

La obra poética de Margarita Abella Caprile es reducida y selecta. Consta de Nieve (1919), Perfiles en la niebla (1923), Sombras en el mar (1930), 50 poesías (1938), ${ }^{1}$ antología de los anteriores, Sonetos (1931), La miré con lágrimas (1950). Desde sus primeras composiciones, que datan de 1916 cuando todavía era alumna del Sagrado Corazón y su inspiración se limitaba al mundo familiar, colegial, o nacional, se caracteriza su verso por el buen gusto. En poemas iniciales de ritmos y tono modernistas, reminiscentes de literatura, como "El gaucho" escrito en cláusulas rítmicas, si bien carecen de originalidad, apuntan altas cualidades estéticas y prometen versos como los de su primer libro Nieve, de gran corrección formal y refinamiento de espíritu. Entre las poesías de este volumen se encuentran algunas honda y sencillamente conmovedoras, tales la titulada "Nieve sobre Buenos Aires". Se percibe aquí la emoción de sí misma a través de una visión literaria de la vida, al contemplar la blancura y pureza de la nieve símbolo de sus aspiraciones y sus ensueños:
¡Ah; lograr, en un rapto indescriptible;
estrechar con abrazo sin medida, toda esta blanca esencia incorruptible e incrustarla en el fondo de mi vida! (pág. 9).

Recatado romanticismo que se refugia en un neoclasicismo modernista para alcanzar su más límpida y sencilla expresión dentro de una delicada atmósfera espiritual. A través de ella, las angustias de la juventud se despojan de su materialidad para encauzarse hacia una imperceptible filosofía, algo contagiada de melancólico sentir pero iluminada y espiritualizada por la fe en la vida, y así siempre a distancia del atormentado dolor moderno. Todo lo más expresa un profundo sentimiento de soledad pero sin abandonarse a la amargura, ni llegar jamás al pesimismo filosófico que tan lejos nos lleva a veces de los sentimientos verdaderos.

1 A este libro, publicado en 1938 por la Comisión Argentina de Publicaciones e Intercambio, pertenecen los trozos de poesía que citamos más adelante. 


\author{
¡Ah, qué desolación y qué cansancio \\ este inútil luchar; \\ cada espíritu es como una isla \\ a la cual nadie, nunca, arribará! (pág. 22)
}

Lo que prevalece en la poesía de Margarita Abella Caprile es la serenidad, a la cual llega convirtiendo la vida en arte, como dice en "Consagración" y también -esto no es paradoja - vertiendo el arte en la vida para serenar la dolorida emoción y comunicarle una diáfana claridad. Su dolor se hace "cotidiana alborada" y sale y se pone como un "Sol de oro".

Fino, sobrio, intuitivo, es su segundo libro. En él, los contornos del sentimiento se difuminan en un paisaje interior de neblina. Las notas simbolistas del musical Verlaine hacen eco en los silencios que flotan tristes en la noche; el tono suavemente escéptico de su filosofía pasa del sensitivo refinamiento francés al nostálgico ensueño nórdico. Así es "Paisaje gris”, quizás la más original variación del conocido poema verlaniano:

\author{
Tarde otoñal; las hojas \\ que ruedan por el suelo, \\ inician su angustiosa despedida; \\ flota un triste silencio \\ en el paisaje gris que va borrando \\ el esfumino de la noche. Siento \\ misteriosos pesares \\ y nostalgias sin fin. Está lloviendo \\ sobre el mar. La dulzura de las gotas, \\ imperceptible para el hondo océano, \\ la bondad de la lluvia que se pierde \\ en el profundo piélago, \\ son como el vano alivio \\ $y$ el inútil consejo \\ que vierten su piedad inescuchada \\ en la amargura de un dolor inmenso. (Pág. 24).
}

En su segundo libro encontramos, no sólo tendencias neoclásicas, sino también verdaderas recreaciones del clasicismo popular que la acercan al Banchs de los romances y que, como en la poesía de Banchs, surge de una inspiración culta y aristocrática nacida de la necesidad de verter en formas sencillas el mundo subjetivo: 


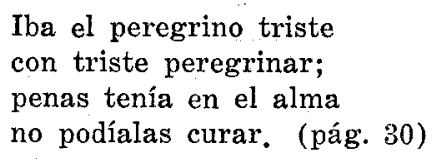

$\mathrm{Su}$ gusto por lo clásico encuentra en el soneto el molde adecuado en que verter la emoción de sus pensamientos que se deshacen en intuición o de sus sentimientos que tienden hacia una casi filosofía mística. La mejor expresión, quizás, de esta identificación de sentimiento místico y esteticismo intelectual se encuentra en su magnífico soneto "Notre Dame de París", visión parnasiana que, al contacto con la diáfana espiritualidad de Margarita Abella Caprile, se desprende lentamente del paisaje que la encuadra para elevarse hacia una intangible región mística. Si por la elegancia, la sobriedad y la selección se acerca a Enrique Banchs, se diferencia de él por el intenso índice romántico de su temperamento poético.

Todavía más refinada en Sombras en el mar, más profunda y siempre sencilla, sin abdicar sus guistos tradicionalistas, ni su innato romanticismo inicial casi siempre subrayado en el último verso, Margarita Abella Caprile, en pleno dominio de su personalidad poética, alcanza acentos intensos, conmovidos, al tratar de temas vernáculos, y logra expresar las experiencias de la vida en un inmaterialismo poético de trazos sobrios carente de abstracciones u oscuridades. Así habla en la última estrofa de "Esa es toda la vida":

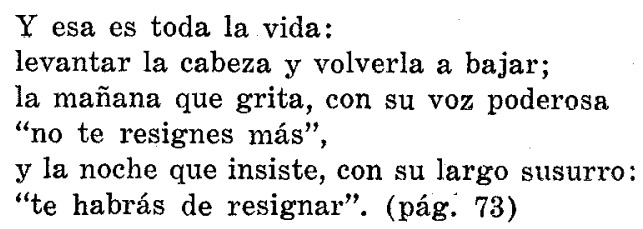

Entre las influencias que han creído verse en la obra de Margarita Abella Caprile, se mencionan las siguientes: la de Delmira Agustini, por el uso del simbolismo del blanco, que le inspira poemas como "Estoy sola" y el título de su primer ljbro Nieve;" la de la condesa de Noailles y de Juana de Ibar-

2 M. Dantas Lacombe, Margarita Abella Caprile. Su obra poética, Buenos Aires, "Club Argentino de Mujeres", 1932, pág. 9. 
bourou en su período de formación ; 3 la de Amado Nervo por el misticismo que envuelve su emoción $;^{4}$ la de Francis Jammes por la sencillez religiosa con que expresa el sentimiento de la naturaleza; ${ }^{5}$ la de Bécquer por la inmaterialidad y sutileza del sentimiento; la de Baudelaire (no vemos muy bien esta última); la de Shelley y de Keats por la transparencia luminosa del sentimiento hacia el paisaje $;^{6}$ la de Verlaine por el encanto de lo evanescente. ${ }^{7}$ Nosotros hemos creído ver una fuerte afinidad con Banchs. Desde luego que todos estos poetas leyó Margarita Abella Caprile, y la influencia que hayan podido tener en ella se encuentra fundida en su singular personalidad. De quien más cerca se encuentra, por el espíritu, es de Nervo, como habrá podido verse por los fragmentos citados y, salvadas las distancias, estamos de acuerdo con la siguiente diferenciación que hace A. Cónsole entre ambos:

Nuestra poetisa ha encontrado en el gran lírico mejicano el Maestro... Lo mismo que el cantor de Serenidad siente la voz del infinito que le habla de Dios... Pero fuera del misticismo... se diferencian fundamentalmente. Amado Nervo quemó el incienso de su espíritu en aras del Amor... Nuestra poetisa, por el contrario, es todo renunciamiento a los bienes de la tierra. 8

Acertada observación que apunta además un rasgo pocas veces notado del temperamento ascético de la mujer, vivamente presente en la expresión poética de Margarita Abella Caprile.

En la última parte de 50 poesias, subtitulada "Ultimas poesías", se advierte una tendencia hacia el ultramodernismo, no tanto por la forma como por el concepto de la metáfora. Lo mejor suyo sigue siendo lo clásico de forma y los sonetos de

3 J. Carrera, "Margarita Abella Caprile", América, Revista de la Asociación de Escritores y Artistas Americanos, La Habana, 1941, XII, 74.

4 A. Cónsole, "Nuestras poetisas de hoy", en Dos conferencias literarias, Bue. nos Aires, Ferrari Hnos., 1935, pág. 26.

5 C. González Ruano, Literatura americana. Ensayos de madrigal y critica. I; Poetisas modernas, Madrid, Imp. Artística de Sáez Hnos., 1924, pág. 91.

- M. de Vedia y Mitre, "Un juicio sobre Perfiles en la Niebla", La Nación, Buenos Aires, junio 1, 1924.

7 "Perfiles en la niebla por Margarita Abella Caprile", El Sol, Madrid, junio 21, 1924.

8 A. Cónsole, loc. cit. 
Margarita que han ido apareciendo periódicamente en $L a$ Nación durante estos últimos años, de trazo seguro, de sostenido estado poético, siguen afirmando la excelencia de su última inspiración. En su "Soneto del verso difícil" nos dice cuál es su actitud frente a la nueva poesía, en unos versos tersos que siguen siendo tan tradicionales como antes pero con esa nueva dificultad moderna de la palabra exacta:
Abstraída en ingrávidas canteras hierro mármol difícil para el verso; largas angustias, al rendir!o terso logran un sueño de almas venideras.
Guiando emoción por sólidas riberas, puliendo ritmos contra el don adverso, cuando, al fin, capta forma lo disperso premio vibrante alcanzan mis esperas.
Sólo el paciente devenir perdura. Graves milenios de tenaz clausura prestan al oro dignidad sintética;
pausado, el roble, a su destino sube; las nieves altas, concisión de nube, lentas destilan transparencia hermética. (pág: 115)

Consideramos a Margarita Abella Caprile fina y auténtica poetisa cuyo innato y nostálgico romanticismo dominado por la sobriedad de la expresión llega a una intensidad pocas veces igualada al entregar a una forma casi siempre clásica su aristocrático y diáfano sentir. Bien le sienta la definición que de ella hace María Monvel: "Soprano ligera de la lírica americana".

Helena Percas

Grinnell College

\section{ARTURO TORRES-RIOSECO}

RTURo Torres-Ríoseco es un hombre lleno de equilibrio, de
serenidad, de placidez. Su cabeza leonina, de cabellos
muy blancos, se yergue airosa sobre unos hombros fornidos de
nadador o luchador. Torres-Ríoseco es corpulento, de estatura 
más que mediana, de andar reposado y firme, de ademanes lentos y mesurados. Su ancha faz sonrosada y benévola irradia una juventud y una salud que contrastan con la blancura de su cabellera lacia. El cigarrillo humeante nunca se desprende de sus labios, ni al volverse colilla. Esto, sin embargo, no estorba el sereno fluir de su palabra ni el mirar sostenido de unos ojos inteligentes que observan tranquilos y amables, al interlocutor, tras unos lentes de sólida armadura negra.

No lejos del campanilo de la Universidad de California se alza el Dwinelle Hall, vasto edificio moderno rodeado de jardines, en que Torres-Ríoseco tiene su despacho. La ventana del despacho da sobre el jardín a la izquierda del edificio. Desde esa ventana se columbra un gran trozo del cielo azul de California y se oye el incesante rumor de los surtidores que riegan los arriates cercanos. El despacho de Torres-Ríoseco tiene las paredes cubiertas de libros ordenados vertical y horizontalmente en altos estantes. Estos libros son en su mayoría de novelistas, de poetas, de críticos y de ensayistas hispanoamericanos. En el lomo de muchos de los libros que están en el estante frontero a la mesa de trabajo del profesor, llenando más de un anaquel, se lee el nombre de éste, en caracteres dorados o negros. Sobre la mesa se apila un rimero de volúmenes recién recibidos de México, de Cuba, de Colombia, de Chile y otros países. Junto al primero de libros por leer hay otro de cartas estampilladas abigarradamente, cuyos sobres aún no rasgados, exhiben membretes de universidades, de institutos, de academias y de correspondientes individuales de las Américas. Se advierte que en este despacho se desarrolla una labor sin prisa pero constante y tenaz, conforme a un método regular e inalterable, al que no perturban las interrupciones. Porque hay muchísimas interrupciones. Al profesor Torres-Ríoseco hay que consultar a toda hora sobre múltiples asuntos académicos o administrativos pues de su dictamen depende la adopción o rechazo de ésta o aquélla política universitaria en que participa el departamento de que él es figura descollante.

No pasan diez minutos sin que suenen en el cristal esmerilado de la puerta del despacho los nudillos de un colega, de una secretaria, de un editor de libros académicos, de un estudiante que está escribiendo una tesis doctoral. Torres-Río- 
seco interrumpe la lectura de un informe o la redacción del borrador de una carta y recibe al visitante con calmosa amabilidad. A las preguntas que se le formulan, no rara vez en tono de reprimida preocupación, el profesor contesta con una salida ingeniosa que corrige la aparente gravedad de un asunto. $Y$ al par de esta respuesta humorística, que a menudo indica con sencillez la solución de un problema, se produce un ligero desprendimiento del cigarrillo adherido a un extremo de su sonrisa. Con amplio ademán sosegado el profesor sacude la ceniza caída sobre sus solapas. Tras este ademán habitual la dificultad planteada en el diálogo parece desvanecerse como aventada con la ceniza, y el visitante se despide. Torres-Ríoseco entonces reanuda tranquilamente la tarea interrumpida.

Es evidente que este hombre aún joven y fuerte en la plena madurez de la existencia, no ha sacrificado el ejercicio del arte de vivir y de convivir, como otros eruditos, al conocimiento obsesivo del mundo de los libros, aunque se ha pasado toda una vida leyéndolos o escribiéndolos. Pero su gran cultura libresca en vez de limitar su visión a la distancia que media entre los ojos y las páginas impresas y de dejarla fija en trasmundos de fantasía o de abstracción, se la ha agilitado para proyectarla quieta y hondamente sobre el espectáculo de lo que acontece en el aquí y en el ahora, y para penetrar con genuino interés humano en el espíritu de éste o aquel interlocutor, dsconocido o famoso, con quien departe en el atareado fluir de sus horas.

Se adivina en Torres-Ríoseco a un espectador afable aunque un tanto irónico de las flaquezas humanas, a un conocedor benévolo de los hombres y, sobre todo, de los escritores. La presunción, la egolatría, la petulancia, no le incomodan ni irritan sino que, por el contrario, le divierten. Un humorismo sin sarcasmo parece ser la válvula de escape de su tranquila tolerancia para con las debilidades humanas. Sabe él que no hay virtud sin limitación, ni cualidades, por excelsas que sean, sin el contrapunto de los defectos. Y puede él por eso dosificar magnánimamente la admiración y la ironía.

En suma, este profesor que ha sido pionero infatigable en la América anglosajona en pro del estudio y valoración de una cultura ignorada (o negligida, como diría Jorge Luis Bor- 
ges), ha sabido como pocos evitar los peligros del ensimismamiento profesoral. Ha pasado por la prueba de fuego de la vida académica norteamericana que es toda prisa, tensión, horario estricto, angustia del minuto, y se ha mantenido exento del contagio del atolondramiento que convulsiona los claustros cuando suenan las campanillas y corren por ellos muchedumbres presurosas. $Y$ sobre todo se ha mantenido inmune a ese mal no insólito en los intelectuales, el cual suele manifestarse en nerviosa inquietud azorada o en indiferencia abstraída y remota para toda incitación transeúnte.

Hace más de veinticinco años que escribió Federico de Onís :

Torres-Ríoseco es joven, pasada la flor de la juventud, maduro ya. Su estancia en los Estados Unidos, precisamente en los años formativos, no le ha hecho perder su carácter nativo chileno; no ha hecho de él lo que con feliz expresión puertorriqueña se llama un pitiyanki. Al contrario, lejos de la tierra y el ambiente propios, lo nativo en él se ha depurado, acentuado y universalizado gracias a la influencia extranjera bien asimilada. ${ }^{1}$

Algo semejante al elogio de este chilenismo depurado iba a decir más tarde Gabriela Mistral:

Oir hablar a Torres-Ríoseco es saber que él celó su llama a la intemperie de la extranjería, que la veló con sustento y atizadura. Pueden buscársele en su charla los destrozos del destierro en la sintaxis y las marcas del cartaginismo en el vocabulario. No se les halla. Se enroló en las tropas de Aníbal, pero habla todavía en el patio de la casa familiar o bajo el parrón talquino. ${ }^{2}$

Tanto Federico de Onís como Gabriela Mistral celebran este triunfo de la autenticidad de la persona en el hijo de Talca exilado voluntariamente en el pais de hierro, atribuyéndolo, en mayor o menor grado, al cultivo de la poesía. Lo que no señalan es que el cultivo de la poesía puede constituir a su vez un ejercicio peligroso, como el de manejar un arma de doble filo, para la preservación de la calidad humana más sobresaliente en Torres-Ríoseco. Esta calidad es la que indiqué al comienzo:

1 España en América, Ediciones de la Universidad de Puerto Rico, 1955, p. 667.

2 Prólogo al libro de Torres-Ríoseco, Cautiverio, México, 1955, pp. 13-14. 
el equilibrio, la serenidad, la placidez. Porque este hombre imperturbable y benévolo domina a la perfección un arte acaso más difícil que el de versificar con finura, que es el de vivir con plenitud y sosiego, armonizando el saber y la sagesse.

Torres-Ríoseco, que ha logrado en el arte de vivir la armonía de los contrarios, la ha también perseguido en el arte de rimar. Se ha dicho hace muchos años, y Díez-Canedo lo ha repetido, que en Torres-Ríoseco poeta, libran batalla la espiritualidad y la sensualidad. ${ }^{3}$ Esto se afirmó a propósito de los poemas de En el encantamiento y es todavía cierto en el libro de versos más recientes que se titula Cautiverio. Se advierte hoy, sin embargo, que la batalla entre espiritualidad y sensualidad no se decide a favor de ésta o de aquélla, porque el resultado es otra forma de armonía vital:

No es esencial que viva así violento el fuego de este amor apasionado; no es necesario que yo esté extasiado frente a un milagro de descubrimiento.

No es justo que se pierda en un momento lo que pudiera ser eternizado ni es justo que ande siempre torturado sometido a mi propio sentimiento.

Más natural sería estar atento al desdoblarse de tu pensamiento, a todo acto sutil y razonado

que te revele en actitud y acento, para entregarte pura en el intento de definir tu ser iluminado. ${ }^{4}$

-En el discreteo amoroso de este soneto en que resuenan junto a las vivencias genuinas del poeta ecos antiguos, se advierte la lucha de lo pasional y de lo espiritual, así como el afán de conciliar o superar el antagonismo: ni pasión violenta ni éxtasis pasivo. En los tercetos el poeta aspira a lo que tras-

3 Letras de América, Colegio de México, 1944, p. 393.

4 Cautiverio, p. 38. 
ciende el deseo y a la par escapa a la pasividad del éxtasis. Esto es, a lo que es más natural, a lo que está más en armonía con su natural: el logro de una serenidad que sea armonía en el ser del amador, la cual serenidad permita a éste definir "el ser iluminado" de la amada. De este modo sensualidad o pasión, espiritualidad o arrobamiento, se funden y trascienden en atenta y serena delectación, en armonía de contrarios. Así el conflicto expresado en los cuartetos halla su solución en los tercetos en que el anhelo final se apacigua y purifica.

En la más reciente obra poética de Torres-Ríoseco se transparenta el afán ya aludido de lograr en el arte la aspiración de serenidad realizada en la vida, en la preferencia por los temas a que anima el ideal de placidez, de equilibrio, de simetría en los trabajos humanos. Sirva de ejemplo el soneto en honor del autor de Alsino en que se elogia la vida de Pedro Prado como

$$
\begin{aligned}
& \text { Vida de placidez y simetría, } \\
& \text { sentimiento e idea, musgo y roca... }
\end{aligned}
$$

y en que el ideal del hombre y del artista aparece como el esfuerzo triunfante de imponer a la existencia y al arte una norma de moderación, de serenidad, de ecuanimidad:

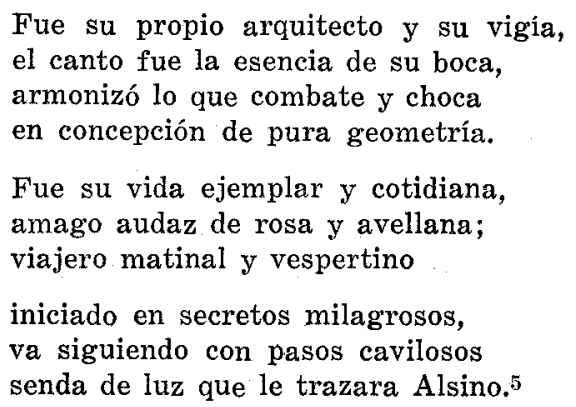

Como se ve, el soneto exalta la vida armoniosa del sentir y del pensar, la igualdad de ánimo a la hora de los dos crepúsculos, la estimación de la rosa sin desdén de la avellana. Es decir, la vida como serena plenitud a través de lo bello y lo

5 Ibid., p. 49. 
vulgar, de lo insólito y lo cotidiano. Todos los símbolos del soneto revelan el mismo desiderátum vital y artístico que, repito, consiste en la consecución estable de una armonía hecha de tensiones y antagonismos.

En el poema "Hechos pasados" Torres-Ríoseco hace una evocación de sucesos como de pesadilla que reaparecen en su mente en una pululación caótica. Este, como algunos otros poemas de Cautiverio es acaso un experimento o ejercicio en que busca formas de expresión acorde con el espíritu de la poesía de vanguardia:
Pasan por mi cerebro viejas películas, con hombres vestidos de payasos y con gestos mecánicos, y mujeres de alambre con zapatos plomizos pasan sobre mi fiebre, pasan en mis insomnios. Murallas carcomidas de lluvia en las que quedan. las lentas acrobacias de los caracoles, caballos de carrera dormidos en la greda de los caminos... ${ }^{6}$

Poesía aluvial es ésta, que arrastra sobre el fondo del subconsciente una carga pesada de detritos de lo que ha sido vívida experiencia un día y hoy retorna en visión sórdida y deprimente:

$$
\begin{aligned}
& \text {... buques en océanos de grasa, hediondos } \\
& \text { a pescado, a pintura, a cocina y a tedio } \\
& \text { fantasmas en las noches sudorosas del Trópico, } \\
& \text { ebrios de luna, de whisky, de mujeres y póker...7 }
\end{aligned}
$$

Ha abandonado Torres la euritmia del soneto, la contención de las medidas fijas y, además, ha abandonado ese estar sobre sí mismo que es la eutrapelia de las emociones. Pero al terminar el poema el caos desaparece y, del pasado total de la vida del poeta, se borran las imágenes de pesadilla: es esto el recobro de la serenidad perdida en instantes de espiritual laxitud, porque ya

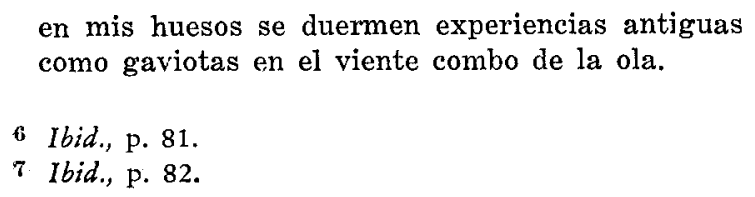


Ni emoción ni sollozo, ni realidad bajo el sueño de las mareas, todo queda cubierto en lejanías difusas y sin carácter y mi voz se domina y adquiere apariencia de cosa humana en la alegría sin énfasis de los hechos pasados. ${ }^{8}$

Resulta, pues, que ese mundo de desintegración que por un momento llenó la mente del poeta no fue nada más que el pasajero predominio de los aspectos sórdidos de la existencia, en una visión, la suya, en que lo bello y lo feo, lo alegre y lo triste, lo noble y lo bajo se necesitan para abarcar el sentido integral de la realidad. $Y$ como este sentido integral de la realidad se ofrece al poeta como el de una armonía de contrarios, la totalidad de su experiencia -es decir, su pasado vital-, readquiere a sus ojos, en lucidez recobrada, su cabal significación. De aquí que todos los hechos pasados, en suma, su vida entera, adquieran finalmente una "alegría sin énfasis", esto es, se sujeten a una perspectiva de serenidad y de equilibrio.

Y este es el mensaje de Torres-Ríoseco que se espiga en sus versos. El mensaje del hombre y del escritor. Mensaje según el cual, a despecho del mal que nos circunda y asecha, es posible lograr en la existencia, con la serenidad, la armonía del saber y la sagesse.

HUgo RODRÍGUEZ-ALCALÁ 